\title{
LA CONFERENCIA SOBRE MIGRACIÓN DE 1932 ENTRE MÉXICO Y GUATEMALA. UNA FRONTERA COMÚN Y DISTINTOS INTERESES
}

\author{
Luis Gerardo Monterrosa Cubías ${ }^{1}$ \\ Universidad Nacional Autónoma de México
}

\section{INTRODUCCIÓN}

\begin{abstract}
A finales de agosto de 1932, las delegaciones oficiales de MéAxico y Guatemala se dieron cita en la capital centroamericana para abordar temas migratorios. Los problemas suscitados en la zona fronteriza propiciaron la reunión. Después de muchos años de tratar estos tópicos por medio de la valija diplomática, los funcionarios por fin estrecharon sus manos. Momentos de discrepancias, tensión y consenso caracterizaron el encuentro de estos hombres de frontera. ${ }^{2}$ Ahora bien, ¿qué se ha escrito sobre la Conferencia de 1932? Las alusiones han sido breves
\end{abstract}

Fecha de recepción: 20 de enero de 2020

Fecha de aceptación: 7 de julio de 2020

1 Programa de Becas Posdoctorales de la UnAm, becario del Centro de Investigaciones Multidisciplinarias sobre Chiapas y la Frontera Sur, asesorado por la doctora Dolores Camacho.

${ }^{2}$ Uso la definición "hombres de frontera" porque la mayoría de los delegados presidían consulados fronterizos u ocupaban cargos vinculados al ámbito migratorio. Gustavo Serrano, por ejemplo, era el encargado de negocios de México en Guatemala, y Andrés Landa y Piña fungía como jefe del Departamento 
porque los investigadores la incluyeron en un recorrido de mediano aliento. Germán Martínez la definió como "el marco diplomático buscado por México para empezar diversas acciones de política agraria y migratoria respecto a la población guatemalteca residente en la zona fronteriza de Chiapas". ${ }^{3}$ Nolan-Ferrell, por su parte, apuntó las discrepancias de los delegados en las sesiones y la iniciativa mexicana de realizar un censo poblacional en Chiapas. Además, sostuvo que la motivación principal de los personeros era controlar la fuerza de trabajo. ${ }^{4}$ Por último, Castillo, Toussaint y Vázquez indicaron que la negociación entablada con el gobierno guatemalteco no desembocó "en acuerdos efectivos respecto del tema migratorio". ${ }^{5}$

Los trabajos conceden pistas sobre la Conferencia y, al inscribirla en una historia de mediano alcance, muestran que los acuerdos forjados en Ciudad de Guatemala no cambiaron una dinámica fronteriza caracterizada por la inseguridad, la arbitrariedad de las autoridades y el desorden. Sin embargo, carecen de una explicación puntual de esta empresa infructuosa. Dicha laguna se genera, desde mi perspectiva, porque sólo mostraron una cara de la moneda: la postura del gobierno mexicano y las incidencias de su frontera sur. Desatendieron, en otras palabras, la contraparte de las negociaciones de 1932 y obviaron por completo al oficialismo guatemalteco: sus intereses y los acontecimientos políticos acaecidos ese año en su territorio. Por esta razón, me propongo examinar en el presente artículo los problemas que suscitaron la Conferencia de 1932, los intereses de los gobiernos y el escenario político guatemalteco para explicar

de Migración. En el bando guatemalteco estaban Sinforoso Aguilar, oficial mayor de la Comisión de Límites, José Pioquinto Pérez, cónsul en Tapachula, y Carlos Auerbach, con la misma investidura en Tuxtla Chico, Chiapas.

${ }^{3}$ Martínez, Plantaciones, p. 31.

${ }^{4}$ Nolan-Ferrell, Construcción, pp. 103-104.

5 Castillo, Toussaint y Vázquez, Espacios diversos, p. 201. 
por qué los acuerdos atacaron el incendio, pero dejaron al rojo vivo las brasas.

Para dotar de contenido mi propuesta y descubrir la carencia señalada fue decisiva la consulta de los acervos documentales de la Secretaría de Relaciones Exteriores de México y el Archivo General de Centro América en Guatemala. El primero contiene la comunicación de los funcionarios mexicanos: sus directrices, un diagnóstico del Soconusco, los puntos que colocaron en la mesa y las actas de la Conferencia. El segundo -que me aclaró muchas dudas- resguarda la preocupación guatemalteca por su frontera suroccidental. Los documentos dejan ver la labor de inteligencia estatal, los reclamos que recibieron por las redadas anticomunistas y sus intentos de blindar la frontera con México y El Salvador para evitar que los “extranjeros indeseables” ingresaran en su territorio.

La combinación de estos materiales con los del Archivo Histórico de Chiapas me brindó un escenario en el cual aparecen una frontera común y distintos intereses. Por ello, decidí iniciar la narrativa con los problemas suscitados en el Soconusco desde 1930, en medio de la crisis económica, para revisar después los intereses de los gobiernos en la Conferencia. Lo último es claro en el caso mexicano, pero contiene un desafío al estudiar la posición del gobierno guatemalteco: "En toda historia siempre hay, en mi opinión -adujo Coetzee-, alguna mirada oculta, una palabra que se calla. Hasta que no hayamos dado expresión a lo inefable no habremos llegado al corazón de la historia”. ${ }^{6}$

\section{LOS PROBLEMAS}

En febrero de 1931, el cónsul mexicano en Ayutla, Guatemala, recibió a dos campesinos que pidieron permiso para ingresar a México en calidad de turistas. Por su apariencia los sometió a un

${ }^{6}$ Coetzee, Foe, p. 141. 
interrogatorio riguroso, generando un nerviosismo que los hizo reconocer el verdadero motivo de su viaje: trabajar con un contratista en Tapachula. El cónsul expresó en su informe que así operaban los finqueros del Soconusco, por lo que era prioritario reforzar los cruces fronterizos de Unión Juárez, Motozintla y Tuxtla Chico.7 La indicación se apegó a la Ley de Migración de 1926, en la cual se establecieron requisitos para ingresar al país sin que fueran cumplidos a cabalidad. Cuatro años más tarde, en lo álgido de la crisis económica, su letra había cobrado fuerza. El excedente de mano de obra en la frontera sur, producto del descenso de la producción cafetalera, y los planes oficiales para ubicar a los deportados de Estados Unidos hicieron que los personeros pretendieran controlar su territorio y a su población. ${ }^{8}$

Para lograrlo intensificaron el registro en los ejidos y las fincas de la franja fronteriza, deportando a aquellos que no tenían pruebas de su nacionalidad mexicana. La población de Chiapas ascendía en 1930 a 500765 habitantes, de los cuales 16385 eran guatemaltecos, es decir, más de $80 \%$ de los extranjeros residentes en la entidad. ${ }^{9}$ La historia de esta presencia se remonta a los tratados de límites de 1882 y fue fortalecida por "los lazos familiares o de comunidad que continuaron vigentes entre los indígenas de la zona -en su mayoría de lengua mam-, que habían quedado 'repartidos' a un lado y otro de la demarcación internacional”. ${ }^{10}$ Cerca de 4000 vecinos de Mazapa, Motozintla y Amatenango, entre otros pequeños poblados, fueron concentrados en el departamento de Mariscal, sin que las autoridades levantaran algún censo. Y precisamente hacia allá se

\footnotetext{
7 AHSREM, exp. IV-395-33.

8 Yankelevich y Chenillo, “Archivo”, pp. 25-42. Pese a la inexistencia de estadísticas formales sobre la tasa de desempleo o subempleo en las fincas, la cantidad de hectáreas para la producción de café en el Soconusco decayó 10\%. Nolan-Ferrell, Construcción, p. 101.

9 Martínez, Plantaciones, p. 26.

10 Castillo, Toussaint y Vázquez, Espacios diversos, p. 201.
} 
desplazaron los agentes de migración, inspeccionando colonias agrarias como Gatica, Manuel Lazos e Hidalgo, formadas por guatemaltecos.

Ciertamente, la expulsión de guatemaltecos de esta región empezó a mediados de los años veinte con la reforma agraria. ${ }^{11}$ Sin embargo, la protección de ciertos políticos a cambio de sus votos los mantuvo a salvo. Así lo denunció el presidente municipal de Tuxtla Chico, reforzando la determinación oficial de suprimir dicho intercambio. ${ }^{12}$ Era momento de apretar las tuercas y combatir la corrupción de los agentes migratorios, su negligencia para ordenar una región descuidada por décadas. Pero este interés encontró resistencias: peticiones a nivel interno y, desde luego, protestas en su vecindad. La Asociación de Cafeteros del Soconusco denunció el acoso de las autoridades hacia la población indígena y humilde, que había creado "un verdadero pánico entre la clase labradora de las aldeas, pues, imposibilitados de obtener el dinero, no se atreven ni a salir a las fincas en busca de trabajo". ${ }^{13}$ En tal sentido, solicitaron en nombre del bienestar agrícola del estado una prórroga para inscribir a los extranjeros y que los braceros vecinos ingresaran sin pagar impuestos para la cosecha de 1932.

Antes del mensaje de los terratenientes, se publicaron en los periódicos guatemaltecos unos artículos de protesta por las disposiciones migratorias y laborales adoptadas en México. Criticaron la deportación de sus ciudadanos, calificándola de injusta por los largos años que llevaban residiendo en la nación vecina. Además, expresaron su inconformidad porque sus comerciantes eran tratados como contrabandistas por las autoridades vecinas. ${ }^{14}$ Por esta fecha apareció otro escrito señalando

11 Nolan-Ferrell, Construcción, p. 85.

12 AHSREM, exp. III-1728-1 (16 de agosto de 1932).

13 AHSREM, exp. III-1728-1, memorándum al embajador de Guatemala en México (14 de agosto de 1932).

14 “Los guatemaltecos en México”, Nuestro Diario (3 ago. 1931), p. 3. 
que el artículo $9^{\circ}$ de la Ley Federal del Trabajo, promulgada en marzo de 1931, era de una flagrante "tendencia nacionalista". ${ }^{15}$ El articulista descalificó el porcentaje de nacionales que debían contratarse, $90 \%$, indicando que era aún mayor al establecido en Estados Unidos. ${ }^{16}$ El gobierno guatemalteco permitió las protestas y decidió atacar a los mexicanos residentes en Guatemala. Ordenaron que para registrarse debían pagar un impuesto y viajar a las cabeceras departamentales. "Como nuestros compatriotas son gente pobre en su mayoría -explicó un personero mexicano-, no están en aptitud de hacer dichos gastos, cayendo sobre ellos la pena de la expulsión."17 Por otra parte, establecieron que todo mexicano que pisara territorio guatemalteco, aunque fuese de tránsito, pagaría cien dólares estadounidenses.

Esta situación prevaleció por algunos meses en detrimento del comercio de la región fronteriza. Así lo informó el presidente municipal de Tuxtla Chico, quien observó cómo las legumbres y objetos de barro provenientes de Guatemala eran retenidos en la frontera por los elevados impuestos. Además, lamentó que la carretera y el puente que se construía sobre el río Suchiate no sirvieran en el futuro para incrementar las exportaciones mexicanas hacia su vecindad. ${ }^{18}$ Los llamados realizados en ambos países para que las autoridades dirimieran este impase tuvieron eco. El acercamiento inició a mediados de 1931 y meses más tarde acordaron celebrar una conferencia. El canciller guatemalteco se ofreció como anfitrión y los mexicanos pusieron a su disposición su embajada para las reuniones. Gustavo Serrano calificó

15 “Nueva Ley de Trabajo en México”, El Imparcial (4 ago. 1931), p. 2.

16 Secretaría del Trabajo, Origen y repercusiones. Un estudio del contexto en el cual se promulgó la Ley Federal del Trabajo aparece en Knight, "Carácter”, pp. 269-307.

17 AHSREM, exp. III-1728-1, el cónsul general en El Salvador al secretario de Relaciones Exteriores de México (12 de marzo de 1932).

18 AHSREM, exp. III-1728-1, informe al embajador de México en Guatemala (16 de agosto de 1932). 
el encuentro de indispensable y conveniente, "pues de este modo se evitará en lo futuro que se cometan abusos, injusticias y molestias a los ciudadanos de ambos países". ${ }^{19}$ Los invitados partieron en ferrocarril hacia Guatemala, realizando una escala en Chiapas para recopilar información de su región fronteriza.

\section{LOS INTERESES DEL GOBIERNO MEXICANO}

Los delegados mexicanos arribaron a Ciudad de Guatemala en la segunda quincena de agosto de 1932. Allí los recibió su representante, Gustavo Serrano, con el que intercambiaron datos sobre la frontera sur y la situación política local. Llegaron al país vecino luego de las fiestas en honor de la virgen de la Asunción -nombre del valle que alberga la capital-y las redadas anticomunistas del mes de enero. Decidieron reunirse entre ellos por la mañana para unificar criterios y después lanzarse a la discusión con los anfitriones. La conferencia se inauguró el 22 de agosto en el recinto de la embajada de México. Aquel día, las delegaciones posaron para el fotógrafo del rotativo oficial, El Liberal Progresista, en medio de un salón engalanado por una mesa de madera y un librero (véase la foto 1). ${ }^{20}$ Los mexicanos tenían una tarea retadora: negociar con los designados de un gobierno que había cobrado venganza por sus medidas en la zona fronteriza.

Los visitantes eran hombres de frontera, trabajaban en la región y conocían de primera mano la situación que imperaba. Muchos de ellos lidiaban con los problemas que la emisión del ordenamiento migratorio y laboral había desnudado. Con frecuencia recibían quejas de la residencia irregular de numerosos guatemaltecos en la región fronteriza y el ingreso ilegal de miles de braceros para la cosecha del café en las fincas del Soconusco.

19 AHSREM, exp. III-1728, el embajador mexicano en Guatemala al secretario de Relaciones Exteriores de México (20 de abril de 1932).

20 “Inauguradas las Conferencias sobre migración”, El Liberal Progresista (22 ago. 1932), pp. 1-8. 


\section{Foto 1}

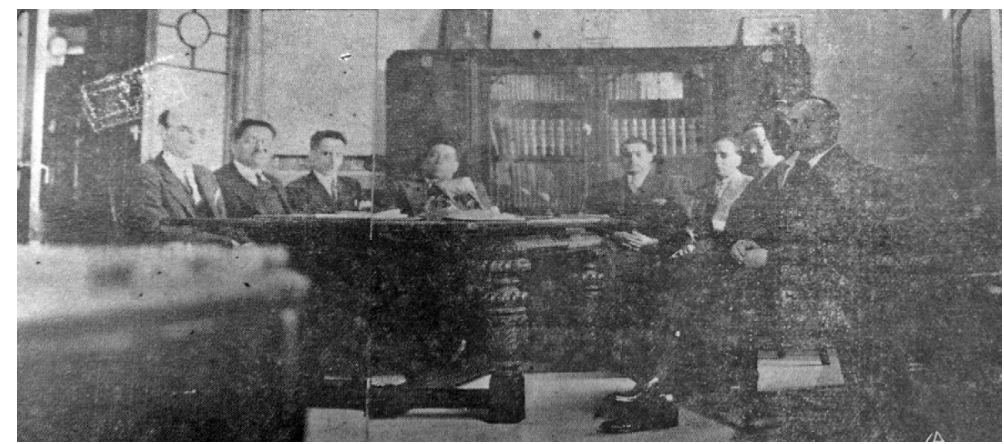

“Inauguradas las conferencias sobre migración”, El Liberal Progresista, Guatemala (22 ago. 1932), pp. 1-8.

A estas alturas el gobierno posrevolucionario cargaba el peso de un descuido prolongado de su frontera sur, el cual desencadenó un escenario confuso y arbitrario. ${ }^{21}$ Confuso por la dificultad de establecer la nacionalidad de muchos individuos que exigían tierras, y arbitrario porque los finqueros y políticos chiapanecos empleaban este limbo al compás de sus intereses. En pocas palabras, el problema agrario de la zona sur -según la definición oficial- tenía diversos protagonistas. Uno de los requisitos para comenzar a ordenar la casa era frenar la inmigración ilegal con la ayuda del gobierno guatemalteco; empero, la exclusión de los vecinos de las tareas agrícolas no fue bienvenida unánimemente.

Los miembros de la Cámara de Comercio de Tapachula externaron su inconformidad en septiembre de 1931. En una carta dirigida a las autoridades de Gobernación criticaron que

${ }^{21}$ Germán Martínez se refirió al espacio mexicano como continuidad del paisaje guatemalteco, considerando que internarse en México antes de 1920 no era ningún problema. "Incluso por motivos naturales se originaron masivos procesos migratorios hacia México, como el ocurrido por la erupción del volcán Santa María en 1902", MarTínez, Plantaciones, p. 32. 
el problema migratorio del estado se analizara exclusivamente desde su legalidad, soslayando la economía del estado. Además, defendieron la contratación de braceros guatemaltecos para desempeñarse en las fincas de café porque eran los que mejor se adaptaban a la inclemencia climática. En su misiva señalaron "la obra civilizadora" que realizaban con los indígenas de San Juan Chamula, Chiapas, a quienes educaban y alimentaban. Sin embargo, indicaron que los braceros del estado eran insuficientes. Por eso recurrían a los guatemaltecos, mismos que atendían su llamado porque la jornada laboral en México, a diferencia de su país, se limitaba a ocho horas y el estipendio era mayor. "No hay preferencia en ningún sentido por una u otra nacionalidad en los salarios, como ciertos informantes han querido hacer creer", ${ }^{22}$ adujeron los signatarios.

Meses más tarde, cuando la tensión fronteriza aumentó, los finqueros también alzaron su voz. Criticaron el impuesto que los braceros guatemaltecos debían solventar y los trámites engorrosos estipulados. Al igual que los comerciantes de Tapachula, calificaron a los vecinos como los únicos habituados a las condiciones de la zona y, por lo tanto, solicitaron que se les eximiera del pago. El argumento de los terratenientes era el mismo: el fruto de los arbustos se pudriría sin los guatemaltecos y ante la crisis económica esto acarrearía la bancarrota del estado. ${ }^{23}$ Empero, las autoridades federales dudaron de su veracidad. Gracias a los personeros destacados en la región sabían que los finqueros pagaban menos a los extranjeros y por esta razón habían boicoteado las disposiciones migratorias desde $1926 .{ }^{24}$

\footnotetext{
${ }^{22}$ AHSREM, exp. III-1728-1 (5 de septiembre de 1931).

${ }^{23}$ AHSREM, exp. III-1728-1 (14 de agosto de 1932).

${ }^{24}$ Un ejemplo de los llamados infructuosos es la petición del encargado del servicio migratorio de Tuxtla Chico, Chiapas, al gobernador del estado en abril de 1927: "Suplico a usted que, por conducto de las Autoridades Municipales, se sirva de exhortar a las compañías o dueños de fincas cafeteras para que no empleen braceros extranjeros que no hayan hecho su entrada al país, sujetándose
} 
Además, la situación era intrincada debido a la protección que los gobernadores daban a los finqueros. Una alianza caracterizada por signos palpables y un elemento estructural. Entre los primeros sobresale el dinero que los terratenientes concedían para edificar carreteras, como ocurrió con Raymundo Enríquez en 1930, obsesionado en legar caminos sin afectar los intereses de los productores del Soconusco. ${ }^{25}$ En el plano estructural estaba la economía regional, basada en gran medida en los productos de exportación. Esto provocó una dependencia de la administración estatal de las ganancias del rubro, a tal punto que "desmantelar la estructura económica significaba también derribar al mismo gobierno". ${ }^{26}$

Por todo lo indicado, no es extraño que Enríquez remitiera un informe a los delegados de la Conferencia, manifestando que los braceros guatemaltecos eran imprescindibles para la economía estatal y que las tierras sin cultivar abundaban para "cooperar con el gran problema nacional". ${ }^{27}$ Las palabras del gobernador conducen al otro detonante del renovado interés oficial por Chiapas: posicionar en esas parcelas a los mexicanos expulsados de Estados Unidos en plena crisis económica. A mediados de 1931, el presidente Pascual Ortiz Rubio recibió un memorándum del Departamento de Migración. Abordaron "el problema agrario de la zona sur" y determinaron que era imperioso hacer cumplir las disposiciones migratorias en Chiapas para evitar la internación de los braceros guatemaltecos, estimados en unos 5000 para la cosecha del café. Todo con el objetivo de "encausar hacia los centros en que pudieran

\footnotetext{
a los requisitos que previene la ley vigente sobre Migración”. AHCH-CUID, IF, exp. 320 (23 de abril de 1927).

25 Benjamin, Chiapas, pp. 196-205. En abril de 1930 los cafeticultores del Soconusco donaron 75000 pesos mexicanos para construir la carretera de Arriaga hacia Tuxtla Gutiérrez. AHCH-CUID, CRE, exp. 173.

26 Spenser, Partido, p. 17.

27 AHSREM, exp. III-1728-1 (20 de agosto de 1932).
} 
encontrar ocupación los mexicanos que a diario y por centenares nos deportan de los Estados Unidos". ${ }^{28}$

Alan Knight calculó en más de 300000 los trabajadores migrantes que deportaron del coloso del norte, ${ }^{29}$ mientras que Mercedes Carreras examinó la intervención del gobierno mexicano: su política de repatriación y la llegada de los expulsados. Diversas instancias se coordinaron para engrosar el sistema productivo. Los gobiernos estatales, por ejemplo, indagaron si tenían tierras disponibles para crear colonias agrícolas. "De todos los informes se deduce -apuntó Carreras-que los estados cooperantes fueron Tabasco, Chiapas, Oaxaca, Nayarit e Hidalgo, que ofrecieron zonas nacionales y los aperos de labranza necesarios para empezar." 30 A pesar de la propuesta de los gobernadores sureños, y del proyecto federal de colonizarlos, la mayoría de los retornados optaron por Coahuila y Sinaloa. El gusto por el norte quedó demostrado, pero la iniciativa oficial develó nuevamente la precariedad de Chiapas y suscitó la animadversión de algunos sectores hacia los guatemaltecos.

La persecución desatada en 1930 tuvo una dosis de nacionalismo y xenofobia: aristas que suelen exacerbarse con las crisis económicas. Ciertos funcionarios acuñaron la consigna "México para los mexicanos" mientras inspeccionaban las fincas; además, tomaron acciones para concretarla. Así lo hizo el encargado del consulado de Ayutla, Guatemala. A principios de 1931 pidió una reunión al agente de migración de la subdelegación de Mariscal, Chiapas, para diseñar estrategias que frenaran la inmigración ilegal de los trabajadores guatemaltecos, estimándolo “de suma importancia en vista de existir en nuestro país el problema de los sin trabajo". ${ }^{31}$ Por estas fechas apareció en la prensa mexicana una campaña en la cual se solicitó erradicar la "invasión

28 AHSREM, exp. III-1728-1 (15 de junio de 1931).

${ }^{29}$ KNIGHT, “Carácter y repercusiones”, pp. 269-307.

30 CARreras, Los mexicanos que devolvió la crisis, p. 116.

31 AHSREM, exp. IV-352-33 (3 de febrero de 1931). 
guatemalteca" para encomendar las labores agrícolas a los mexicanos. "La mayoría son apellidos maya quichés -subrayaron los denunciantes-. ¡ Y esos individuos filtrados quizás ilegalmente, son quienes desplazan a los mexicanos!"32 Inmediatamente, el gobierno mexicano se desmarcó de las opiniones, señalando que no se entrometía en la línea editorial de los periódicos. ${ }^{33}$ Empero, era claro por sus disposiciones que compartían dicha perspectiva. En tal sentido, la "invasión guatemalteca” debía acabar para abrirle espacio a los proyectos nacionales. Por esta razón, no fue casual que la conferencia se llevara a cabo antes de noviembre, mes en el que empieza la cosecha del café, y tampoco que Serrano recorriera el Soconusco antes de reunirse con los delegados guatemaltecos.

El embajador llegó a Tapachula el 7 de agosto de 1932. Visitó algunas fincas cafeteras en compañía del gobernador de Chiapas y el comandante militar de Tapachula. Después, se trasladó a la región de Santo Domingo y los pueblos de Cacahuatán y Unión Juárez, cercanos a la línea divisoria. Finalmente, en el Club Alemán sostuvo una reunión con los finqueros, quienes expusieron su perspectiva de la situación. Serrano admitió en su informe la necesidad de un trabajo conjunto en la región del Soconusco, en el cual participaran diversas instancias, como las de Agricultura y Fomento, Educación, Salubridad, y Trabajo. Todo para realizar una "obra constructiva, de civilización y progreso". ${ }^{34}$ Días más tarde convirtió este propósito en un imperativo al plasmar en su informe un diagnóstico de la zona fronteriza: "Sin extenderme mucho, solamente diré a usted que los asesinatos con arma blanca y de fuego se han venido suscitando en muchos lugares. [...] Pocos días antes de que volviera del Soconusco para esta capital [Guatemala], murieron tres o cuatro personas

\footnotetext{
32 “Los extranjeros. Los mexicanos sin trabajo", La Prensa (23 mar. 1931), p. 3. 33 AHSREM, exp. III-1319-3, el secretario de Relaciones Exteriores de México al embajador mexicano en Guatemala (15 de mayo de 1931).

34 AHSREM, exp. III-1728-1 (27 de agosto de 1932).
} 
de la misma familia, y en ciertos casos han muerto hasta doce personas en un mismo combate". ${ }^{35}$ Reducir la inseguridad de la zona y mexicanizar a sus habitantes integraron los objetivos del gobierno mexicano. ${ }^{36}$ Empresas que, por cierto, debían concretarse sin que sus ciudadanos residentes en Guatemala pagaran el precio.

Hasta la fecha, los que abordaron la temática migratoria en Chiapas durante los años treinta soslayaron la residencia de miles de mexicanos en territorio guatemalteco. Este dato es decisivo para explicar las maniobras del gobierno mexicano ante el problema migratorio, posponiendo, por ejemplo, el registro de los guatemaltecos, y para establecer las razones que lo hicieron negociar con sus vecinos en 1932. En otras palabras, el ordenamiento de la frontera sur debía efectuarse, pero los métodos eran también importantes. De esta forma aplacarían a un régimen que cobraba venganza de sus medidas migratorias con los mexicanos residentes en Guatemala. La evidencia de estas acciones aparece nuevamente en un informe de Serrano. Después de la conferencia solicitó permiso para realizar una gira por el occidente guatemalteco, "donde existen los núcleos más numerosos de mexicanos". ${ }^{37}$ Justificó su viaje con la protección que necesitaban, "pues se han dado casos de atropellos y abusos por parte de las autoridades que, aunque esta embajada ha procurado reprimirlos, es urgente tomar las medidas necesarias para evitar que se repitan".

El 22 de agosto de 1932, el canciller guatemalteco, Alfredo Skinner Klée, inauguró oficialmente la Conferencia. Declaró ante los delegados que el objetivo "era buscar el arreglo

35 AHSREM, exp. III-1728-1, informe sobre las juntas de migración (31 de agosto de 1932).

${ }^{36}$ Un estudio sugerente sobre la labor del Estado posrevolucionario de inventar tradiciones laicas nacionales a través de la educación, aplicado al caso de Chiapas, aparece en Lewis, La Revolución ambivalente.

37 AHSREM, exp. III-276-16 (20 de enero de 1933). 
amistoso de las cuestiones surgidas, sobre la base de la más estricta reciprocidad y tomando en cuenta los intereses de ambos países".$^{38}$ Luego del acto protocolario salió de la embajada y dejó solos a los designados. Los mexicanos, que tuvieron un asesor jurídico nombrado por su gobierno, perseguían tres objetivos que esperaban alcanzar con ayuda del vecino: detener la inmigración golondrina, regularizar el estatus migratorio de los habitantes fronterizos y combatir la inseguridad de esta región. Así, podrían ubicar a los connacionales deportados de Estados Unidos y evitar que los mexicanos en Guatemala fueran molestados. Faltaba esperar, por supuesto, la respuesta de sus interlocutores.

\section{LOS INTERESES DEL GOBIERNO GUATEMALTECO}

Muy poco ofrecieron en materia de compromisos los delegados guatemaltecos a sus pares mexicanos en la Conferencia de 1932. A lo sumo continuar registrando a los mexicanos que residían en Guatemala sin cobrarles un impuesto y exigirles que se desplazaran a la cabecera departamental a solicitarlo. Rechazaron participar en el censo que se efectuaría en la región fronteriza de México, aduciendo que no contaban con los recursos económicos ni personales; y esperando reciprocidad expresaron que nacionalizarían guatemalteco a todo mexicano sin documentos que así lo quisiera. De inmediato, sus pares observaron la reticencia y criticaron la desigual empresa que tenían por delante. No era lo mismo registrar a los 15000 mexicanos que vivían en Guatemala que lanzarse a la ardua tarea de censar a un aproximado de 40000 guatemaltecos instalados en México. La tensión por este punto afloró en las reuniones, pero no impidió que los guatemaltecos plantearan sus exigencias.

\footnotetext{
38 AHSREM, exp. III-1729-9, actas de la Conferencia sobre migración de 1932 (agosto de 1932).
} 
Con el argumento de que el trato hacia los mexicanos era respetuoso en Guatemala, a diferencia de sus vecinos, los delegados guatemaltecos pidieron detener la deportación de sus ciudadanos. Además, solicitaron derogar la restricción establecida en la Ley Federal del Trabajo en cuanto al número de extranjeros permitidos en las fincas y otras empresas. José Pérez, el más aguerrido de los delegados, externó que esta disposición era terrible para sus connacionales, quienes tendrían que volver con las manos vacías al ser despedidos de manera repentina. La delegación guatemalteca transformó las protestas vertidas en sus periódicos en exigencias. Su vecino tomaba medidas para evitar el excedente de mano de obra en medio de la crisis económica y esto afectaba al gobierno guatemalteco, que tenía el mismo problema. Por este motivo deseaban frenar las deportaciones y que la migración golondrina hacia el Soconusco continuara. Así reducirían la presión social del altiplano, temida por los motines suscitados. ${ }^{39}$ Los anfitriones lanzaron sus peticiones, pero tenían también inquietudes inconfesables.

Si bien los guatemaltecos negociaron con sus vecinos, su preocupación por la frontera suroccidental era distinta. Los mexicanos en su territorio no representaban ningún problema. Algunos rentaban tierras, comerciaban y permanecían en las fincas cumpliendo con el trabajo de vialidad. ${ }^{40}$ Jamás se habló en los periódicos guatemaltecos, agresivos con el vecino, de la invasión mexicana y tampoco hubo deportaciones masivas. En tal sentido, los ataques hacia éstos sólo buscaron presionar

${ }^{39}$ Gould, "Dictadores indigenistas", pp. 238-268.

${ }^{40}$ Este dato puede corroborarse en el censo de vialidad del departamento de San Marcos de 1934. Desde enero hasta junio de ese año 532 extranjeros, varones aptos de 18 a 60 años de edad, trabajaron en la construcción o reparación de caminos y carreteras. En el consolidado del informe algunos de los municipios fronterizos o muy cercanos a México registran la mayor cantidad de extranjeros: Malacatán 197, Pajapita 63, Ayutla 51 y Ocós 54. Al revisar la descripción por cada municipio se descubre que la mayoría eran mexicanos. AGCA, B, Jefatura Política de San Marcos, 1934, paquete 1. 
al gobierno mexicano, forzarlo a desistir de sus disposiciones migratorias. A los guatemaltecos lo que realmente los desvelaba era la seguridad de su frontera ante la actividad comunista, la cual, desde su perspectiva, era promovida en México.

Los académicos que abordaron la Conferencia de 1932 soslayaron este aspecto. Nolan-Ferrell y Martínez Velasco tocaron la perspectiva mexicana: analizaron la situación política, económica y social de la frontera sur y las repercusiones de la inmigración guatemalteca. Y a pesar de que la primera evaluó la dinámica sociopolítica de los departamentos fronterizos de Guatemala, sobre todo de San Marcos, su estudio de la Conferencia carece de aclaraciones importantes. ${ }^{41}$ Por ejemplo, el tipo de gobierno con el que los mexicanos negociaron en 1932 y el ambiente político del país vecino. Mi hipótesis es que estos aspectos explican la postura displicente de los delegados guatemaltecos y, a la vez, proporcionan elementos de juicio para entender por qué las tensiones fronterizas continuaron. Pues bien, es momento de voltear los reflectores e iluminar al otro protagonista de la conferencia. Uno que, por cierto, recién había enfilado sus armas para fulminar la acechanza de su enemigo.

El 29 de agosto de 1932, un signo del interés guatemalteco por la frontera fue escrito en las actas. De hecho, lo formularon como una petición. Sinforoso Aguilar trajo a colación una solicitud previamente planteada: que la deportación de extranjeros indeseables de una tercera nacionalidad no se realizara por el país vecino, a menos que hubiera ingresado por allí. ${ }^{42}$ Los mexicanos rechazaron la moción, indicando que su ley migratoria se ajustaba al derecho internacional. Como puede apreciarse, las actas de la Conferencia o el informe del embajador estadounidense, desde los cuales Nolan-Ferrell revisó las juntas, proporcionan pistas, pero no el interés oculto de los guatemaltecos. Para develarlo

\footnotetext{
41 Nolan-Ferrell, Construcción, pp. 125-131.

42 AHSREM, exp. III-1729-9 (agosto de 1932).
} 
debe consultarse la comunicación de sus oficinas de inteligencia, en la cual las alusiones a la frontera con México son abundantes.

\section{EL RECELO ANTE EL VECINO}

Las relaciones entre México y Guatemala distaron de ser cordiales y cercanas en gran parte del siglo xx. El andar de estos vecinos estuvo marcado por la desconfianza, el rencor y las conspiraciones para golpear a un rival que, sin plantarle batalla de manera directa, resultaba molesto. La frontera se convirtió entonces en un lugar de confabulaciones y amenazas. Aquel paraje donde se refugiaban los que planeaban una incursión armada. Episodios de este calado han sido retratados en el terreno historiográfico y literario. ${ }^{43}$ Sobresale en el último la novela El Señor Presidente, con los partes que el mandamás leía de sus corresponsales en la frontera. La trama elaborada por Asturias, inspirada en el gobierno de Manuel Estrada Cabrera (1898-1920), refleja la tensión fronteriza que Guatemala vivió con México y El Salvador en dicho periodo. La primera nación, por cierto, envuelta desde 1910 en luchas e intrigas que marcaron la Revolución. Este escenario político se reconfiguró diez años más tarde: Estrada Cabrera fue depuesto y ese mismo año, 1920, Álvaro Obregón arribó a la presidencia de México. Aun así, la relación entre los liberales guatemaltecos y el régimen posrevolucionario continuó plagada de suspicacias.

El reformismo que el gobierno mexicano promovió y la beligerancia de los sindicatos alarmaron a sus vecinos sureños. "En su visión del mundo -como escribió Spenser-, el agrarismo practicado en México y protegido por el presidente Calles equivalía al comunismo". ${ }^{44}$ Esto lo percibió el embajador de

${ }^{43}$ Zorrilla, Relaciones; Gutiérrez, En el país de la tristeza, y Asturias, El Señor Presidente.

${ }^{44}$ SPENSER, El triángulo imposible, p. 214. 
México en Guatemala, Eduardo Hay, en noviembre de 1930. En esa fecha asistió a una reunión con el canciller Skinner Klée. Éste le expresó que Guatemala vivía una crisis económica severa y que 300 familias salvadoreñas habían solicitado permiso para trabajar allí. Contemplaban exigirles 100 dólares estadounidenses para entrar, y quería saber su opinión. El diplomático le expresó que la medida era lógica y le comentó que en México se había adoptado. Sin embargo, la pregunta fue interpretada en su informe como un deseo de limitar la migración mexicana. No por la crisis económica, "sino porque aquí tienen temor de que el obrero mexicano, conocedor de la fuerza de los gremios $\mathrm{y}$ de sus derechos, venga a enseñar al obrero guatemalteco a defenderse". ${ }^{45}$

A finales de 1930, una grave enfermedad del presidente Lázaro Chacón propició su renuncia, abriendo paso a las intrigas en el ejército y su partido. El cuartelazo que sobrevino y la negativa de Washington de reconocer al militar golpista, Manuel Orellana, favorecieron las aspiraciones políticas de Ubico. En febrero de 1931, cuando los comicios sólo legitimaron su ascenso, un articulista rechazó que fuera antimexicano. Apuntó que había estudiado en esa nación y justificó los fusilamientos que ordenó de ciertos mexicanos cuando ocupó la jefatura política de Retalhuleu. ${ }^{46}$ Sin embargo, un diplomático mexicano se mostró escéptico. En su informe interpretó esta opinión como parte de la gratitud que el autor sentía por sus colegas de la escuela de jurisprudencia en México, donde estudió. ${ }^{47}$ Y, en efecto, acertó.

Ubico reservó sus elogios hacia México para los discursos oficiales, pero mientras los erogaba externaba su desconfianza hacia los diplomáticos de esa nación y permitía que se atacara

\footnotetext{
45 AHSREM, exp. 39-8-81 (17 de noviembre de 1930).

${ }^{46}$ Héctor Samayoa, "Mexicanos y guatemaltecos", El Tiempo (19 feb. 1931). 47 AHSREM, exp. 39-8-82, el encargado de negocios de la embajada de México en Guatemala al secretario de Relaciones Exteriores de México (21 de febrero de 1931).
} 
sistemáticamente en los rotativos al gobierno vecino. En abril de 1932, el gobernante convocó a Gustavo Serrano a una reunión. Luego de la charla protocolar agarró al toro por los cuernos. "Me habló sobre el comunismo -relató el funcionario-. Se muestra muy temeroso de que tal doctrina vaya a incrementarse en Guatemala y aun piensa que en México se encuentra bastante desarrollada." 48 El diplomático intentó disipar este recelo, expresándole que ningún comunista ostentaba un cargo público y que no debía exagerarse la magnitud de tal doctrina. En la entrevista prevaleció una franca cordialidad, como escribió Serrano, pero sus palabras no atenuaron la desconfianza del presidente. Así lo exhibieron los periódicos oficiales.

A comienzos de 1932 apareció un editorial titulado "El comunismo en la América criolla", escrito por el director de Nuestro Diario, el salvadoreño Carlos Bauer Avilés. Adujo que el gobierno mexicano permitía la propaganda comunista y advirtió sobre el peligro que Guatemala afrontaba por su vecindad. ${ }^{49}$ Nuevamente un diplomático mexicano habló con las autoridades de ese país. En su informe expresó que los ataques habían disminuido desde que Eduardo Hay platicó con el canciller guatemalteco, pero recordó que este último le dijo que la prensa, apegada a derecho, no estaba controlada y menos censurada. La sentencia rayó en la ironía, pues era evidente la coacción ejercida. Por ello, el diplomático calificó esta publicación de dolosa y grave..$^{50}$

Los ataques contra México aparecieron, incluso, días antes de iniciar la Conferencia. Esta vez el vocero del partido oficial disparó sus balas. Un articulista calificó a Lombardo Toledano

48 AHSREM, exp. IV-352-33 (1 de abril de 1932).

49 Carlos Bauer, "El comunismo en la América Criolla”, Nuestro Diario (28 ene. 1932).

50 AHSREM, exp. 34-4-29, el encargado de negocios de la embajada de México en Guatemala al secretario de Relaciones Exteriores de México (13 de febrero de 1932). 
y Adalberto Tejeda de desorientados que propagaban el comunismo en la vecindad bajo los designios de Moscú. ${ }^{51}$ Esta muestra de la campaña periodística y el recelo de Ubico explica la postura de los delegados guatemaltecos en la Conferencia. Eran cuadros alineados a la perspectiva oficial, que vieron con recelo a los designados de un régimen que albergaba y coqueteaba con su enemigo. Corrobora esta actitud la cobertura que la prensa de esa nación otorgó a las reuniones en la embajada. Las notas registraron la inauguración y hablaron de la cordialidad imperante. Sin embargo, nunca aludieron a la presencia irregular de numerosos guatemaltecos en México. En su lugar tocaron el tema del turismo, planteando la urgencia de mejorar la red vial y hotelera para fomentar los viajes de mexicanos y guatemaltecos. ${ }^{52}$ Como puede apreciarse, los funcionarios tenían otro interés hacia México. Lo sucedido en su suelo poco antes de la Conferencia brinda pistas al respecto.

\section{LA EMBESTIDA CONTRA EL COMUNISMO}

En septiembre de 1931, el encargado de negocios de la legación guatemalteca en Alemania, José Díaz, remitió un informe a su superior. Había comprado información a un agente francés que vigilaba a los comunistas en Alemania; sus revelaciones eran alarmantes. Manifestó que acababa de organizarse en Puerto Barrios una central moscovita, encargada de la propaganda comunista. Según el espía eran siete los emisarios para Nicaragua,

51 Teófilo Castillo, "Bolcheviquismo disfrazado y comunismo al rojo vivo”, El Liberal Progresista (17 ago. 1932). Sobre Lombardo Toledano véase SPENSER, En combate; y para entender el surgimiento de Tejeda en la Revolución y su actuación como gobernador de Veracruz, a Fowler, "Caudillos".

52 "Fomento del turismo entre México y nuestro país", El Liberal Progresista (30 ago. 1932), pp. 1, 8. La misma tónica prevaleció en el periódico oficial: "Primera reunión de las Conferencias de Migración", Diario de Centroamérica (23 ago. 1932), p. 2. 
Panamá, Honduras, Costa Rica, Colombia y México. Señaló, además, que cuatro agentes partieron rumbo a Guatemala en el mes de julio. El objetivo era infiltrarse en el ejército. El diplomático anotó sus nombres y una descripción de sus labores. Sobre un español de seudónimo Pedro Tabernillas escribió: "Sé que posee algunos papeles falsificados, correspondientes a una firma parisiense, por lo que aparece como comerciante de café. La propaganda escrita la lleva en cofres de doble fondo, para burlar la vigilancia de las autoridades del puerto". ${ }^{53}$

El diplomático solicitó que la información se corroborara y que la policía la utilizara eficazmente, pues su costo fue elevado. Asimismo, indicó que era urgente vigilar la frontera para evitar que los extranjeros contactaran a los "apóstoles del comunismo criollo", aquellos centroamericanos "afectos a tan absurdas doctrinas". Un año antes de esta comunicación, el canciller guatemalteco había recibido una misiva de una agrupación anticomunista de Estados Unidos. La American Vigilant Intelligence Federation, con sede en Chicago, ofreció sus servicios en vista de la actividad comunista que se desarrollaba en esta nación. ${ }^{54} \mathrm{La}$ oferta fue rechazada, afirmando que el gobierno tenía los medios para contrarrestarla. Sin embargo, era claro que algo sucedía y comenzaba a conocerse a nivel internacional.

Sobre la organización de los comunistas guatemaltecos en los años veinte, sus lazos con la Internacional Comunista y la agitación obrera se han publicado sugerentes artículos. ${ }^{55}$ Los académicos abordaron aspectos variopintos, pero coincidieron en tres: el descubrimiento que los obreros hicieron de la huelga como mecanismo reivindicativo, la represión oficial contra los cuadros organizados y su vinculación con el Partido Comunista de México. Esto último adquiere importancia en el

53 AGCA, B, RREE, exp. 672 (30 de septiembre de 1931).

${ }^{54}$ AGCA, B, RREE, exp. 6724 (1ㅇ de septiembre de 1930).

55 Taracena, "Partido", pp. 49-63; Figueroa, "Marxismo", pp. 57-86 y Melgar Bao, "Cominternismo", pp. 135-159. 
presente ensayo, no sólo porque atañe a la historia común de estas naciones, sino por el conocimiento que las autoridades centroamericanas tuvieron de las andanzas de los comunistas mexicanos en la región. ${ }^{56}$

En tal sentido, la información resguardada en el Archivo General de Centro América representa la contraparte de los artículos citados. Es decir, la comunicación de las instancias oficiales para repeler lo que Melgar Bao llamó “el corredor económico, político y educativo” de los disidentes políticos. Una red de contactos que les permitió transitar por Centroamérica cuando la movilización social alcanzó su clímax. ${ }^{57}$ Entre los documentos aparecen misivas e informes sobre la deportación de "extranjeros indeseables"; asimismo, partes de la vigilancia ejercida en la frontera con México y El Salvador. La agitación era intensa cuando Ubico tomó el poder en 1931 y los funcionarios optaron por otorgar una respuesta de doble carril, según Figueroa. Por un lado, la demagogia y la cooptación y, por otro, la represión abierta. ${ }^{58}$ Con el tiempo cobró fuerza la segunda, sobre todo cuando intentaron aislarse del ajetreo político de su vecindad (véase la foto 2 ).

El 11 de enero de 1932, el cónsul guatemalteco radicado en Santa Ana, departamento occidental de El Salvador, remitió a su superior dos ejemplares que calificó de "periodiquitos

56 Jorge Fernández Anaya, miembro del Partido Comunista de México, relató su experiencia en Totonicapán, Guatemala, en una entrevista que concedió a Carlos Figueroa. Corría el año de 1931 cuando se internó en una hacienda de este departamento para organizar una huelga en la que exigieron el pago con dinero en efectivo para los empleados. Al recordar la represión encajada, feroz por ese entonces, indicó que la policía guatemalteca sabía de su presencia, y que en "El Salvador también decían que había un bolchevique mexicano". FigueROA, "Marxismo", p. 222. Acerca de la captura de un comunista procedente de México véase Taracena, "Partido", p. 57.

57 Gould y Lauria, Rebelión, 2014.

58 Figueroa, "Marxismo", p. 76. 
Foto 2

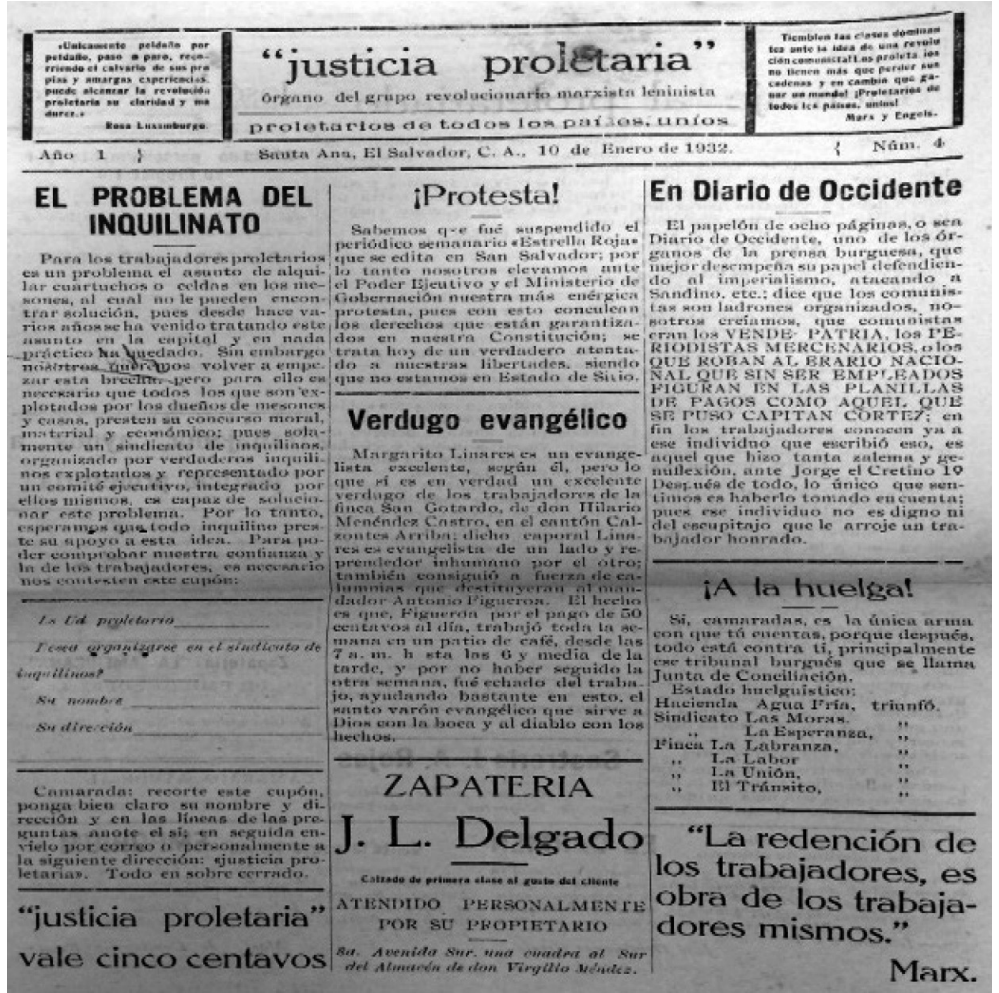

Justicia Proletaria, Santa Ana, El Salvador (10 ene. 1932). AGCA, RE, leg. 6725.

locales". ${ }^{59}$ En sus páginas la propaganda comunista apareció al desnudo. Ciertamente, son joyas documentales que permiten apreciar el activismo desarrollado antes de la matanza de ese año. “¡A la huelga! Sí, camaradas, es la única arma con que tú cuentas, porque después, todo está contra ti, principalmente

59 AGCA, B, RREE, exp. 6725 (11 de enero de 1932). 
ese tribunal burgués que se llama Junta de Conciliación." 60 Y en la esquina inferior derecha de la portada plasmaron unas palabras de Karl Marx: "La redención de los trabajadores es obra de los trabajadores mismos". El cónsul guatemalteco solicitó que las autoridades de su país evitaran la circulación de estas publicaciones. Un llamado similar realizó meses antes Carlos Auerbach, quien fungía como cónsul en Tapachula, Chiapas. En su informe adjuntó un periódico comunista, Gil Blas, editado en ese municipio fronterizo. Días más tarde, el diplomático, designado posteriormente a la Conferencia de 1932, describió las actividades comunistas efectuadas en Tapachula a finales de octubre de 1931. ${ }^{61}$ Ante esta situación, las medidas profilácticas en la frontera eran urgentes, así como la expulsión de los foráneos "indeseables" que recorrían Guatemala.

Fernández Anaya recordó las condiciones adversas que afrontó en esa nación, ya que a la diferencia lingüística se sumaba la poca politización de los indígenas del Altiplano y una represión encarnizada. El mexicano nunca vio tanta marginación como en Guatemala, donde fue capturado junto con otros miembros del incipiente Partido Comunista. ${ }^{62}$ Ese suceso fue la culminación exitosa del trabajo de inteligencia realizado en el periodo, mismo que facilitó la deportación de otro mexicano, José González, quien trabajaba como mecánico pero repartía propaganda subversiva en la capital guatemalteca. ${ }^{63}$

Como puede apreciarse, la represión contra los comunistas y el movimiento sindical antecedió a Ubico, quien después la

\footnotetext{
60 “'A la huelga!”, Justicia proletaria (10 ene. 1932), p. 1.

61 AGCA, B, RREE, exp. 6725 (27 de octubre de 1931).

62 "La pobreza era extrema-recordó Fernández-. Yo vi cómo llevaban a unos peones a trabajar a la bananera, amarrados del pescuezo con un mecate y en fila india, como esclavos. Nunca vi una cosa semejante en El Salvador.” FigueroA, "Marxismo", p. 218.

${ }^{63}$ AGCA, B, RREE, exp. 6725, el director de la Policía Nacional al ministro de Relaciones Exteriores de Guatemala (5 de septiembre de 1931).
} 
encumbraría hasta cimas insospechadas. La cacería de brujas comenzó en diciembre de 1931. En las redadas de ese mes fueron aprehendidos 400 individuos que colmaron las cárceles. ${ }^{64} \mathrm{El}$ régimen prometió un castigo enérgico y ejemplar, culpando al gobierno predecesor de alentar con su pasividad el crecimiento del comunismo. ${ }^{65}$ La empresa suscitó algunos comentarios que enfurecieron al oficialismo. Alberto Masferrer, escritor salvadoreño y distinguido vitalista, restó credibilidad a las acciones y cuestionó que Guatemala estuviera acechada por esta ideología. La respuesta fue vehemente: "No vamos a perder el tiempo en refutar las torpes afirmaciones de Masferrer. [...] Esta acción previsora la pudo realizar el general Ubico, entre otras causas, porque no fue un secreto para él, el golpe que iba a estallar en El Salvador, como en Guatemala y otros países vecinos”. ${ }^{66}$

Esta afirmación tiene sustento a la luz de los informes de inteligencia que el gobierno recibió desde Alemania. De hecho, en octubre de 1932, cuando reinaba una tensa calma, un articulista exaltó la diligencia del diplomático radicado en esa nación, confesando que revisó el informe en el que notificó acerca del arribo de los comunistas extranjeros a Guatemala. ${ }^{67}$ La confesión provocó la ira del signatario. En una carta al canciller la tildó de imprudente y díscola, pues sin haberlo informado por precaución, la legación en Berlín fue custodiada por la policía de esa ciudad desde que se conoció que Juan Pablo Wainwright sería ejecutado. ${ }^{68}$ Estas palabras revelan un aspecto soslayado en

64 "50 comunistas detenidos en varios lugares de la República", El Liberal Progresista (13 ene. 1932), pp. 1, 8.

65 “¿Comunismo entre nosotros?”, El Liberal Progresista (6 ene. 1932), p. 6.

66 "Masferrer, un proscripto social”, El Liberal Progresista (25 ene. 1932), pp. 3-4.

67 "Las investigaciones superficiales", Nuestro Diario (25 oct. 1932), p. 3.

68 AGCA, B, RREE, exp. 6725 (28 de noviembre de 1932). "Wainwright entró a Guatemala en agosto de 1931, después de escaparse del fuerte de Omoa, donde se encontraba encarcelado acusado de ser agitador en las plantaciones bananeras de la costa atlántica hondureña"; TARACENA, "Partido", p. 61. 
la historiografía del periodo: las protestas que estallaron a nivel internacional por la aprehensión y el fusilamiento del comunista de origen hondureño.

Numerosos sospechosos fueron capturados, pero en los archivos puede apreciarse que el objetivo eran los líderes del movimiento comunista. Por esta razón, la información de Juan Pablo Wainwright y Miguel Ángel Vásquez es exhaustiva e incluye sus contactos en México, Alemania, Estados Unidos, Canadá y El Salvador. ${ }^{69}$ El tribunal envió a nueve de ellos al paredón, mientras las torturas siguieron. ${ }^{70}$ Tiempo después, el régimen otorgó su indulgencia. La pena de muerte fue conmutada por 15 años de prisión para la mayoría, menos en el caso de Wainwright, quien cayó fusilado el 4 de febrero de 1932. "El crimen es precioso porque garantiza al gobierno la adhesión del ciudadano", postuló Asturias en El Señor Presidente. ${ }^{71}$ Ubico, al parecer, comprendió bien este precepto, pero no alcanzó a atisbar los reclamos que surgirían en el extranjero.

Ciertamente, el hostigamiento a sus legaciones en Europa y las cartas de protesta que los miembros de la Liga Antimperialista enviaron desde Estados Unidos sólo fueron un trago amargo para los funcionarios. Acaso la confirmación de los vínculos de los comunistas y la amenaza que habían conjurado. Empero, las protestas también irrumpieron en su vecindad. El 12 de febrero de 1932, el embajador reportó un atentado a la casa de la legación en México. Sus paredes amanecieron manchadas con leyendas altisonantes: ¡Viva la juventud comunista! ¡Abajo el asesinato de los once comunistas en Guatemala! ¡Muera Ubico! ¡Viva la URSS! (véanse las fotos 3 y 4). ${ }^{72}$ Además, hallaron cascos de

\footnotetext{
${ }^{69}$ AGCA, B, RREE, exp. 6725, el director general de la Policía Nacional al ministro de Relaciones Exteriores de Guatemala (30 de enero de 1932).

70 Obando, Memorias.

71 Asturias, El Señor Presidente, p. 75.

72 AGCA, B, RREE, exp. 6725, el embajador guatemalteco en México al ministro de Relaciones Exteriores de Guatemala, México (12 de febrero de 1932).
} 
Foto 3

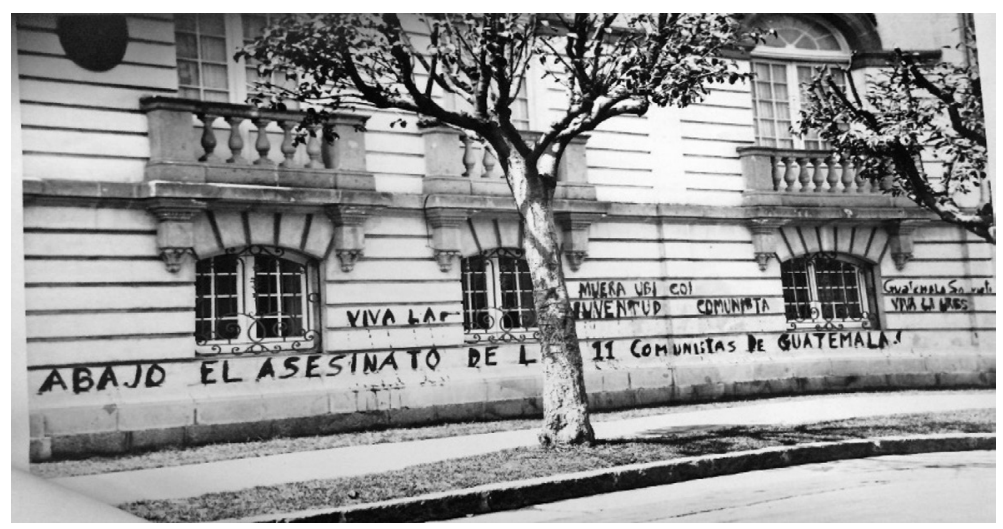

AGCA, RE, leg. 6725.

Foto 4

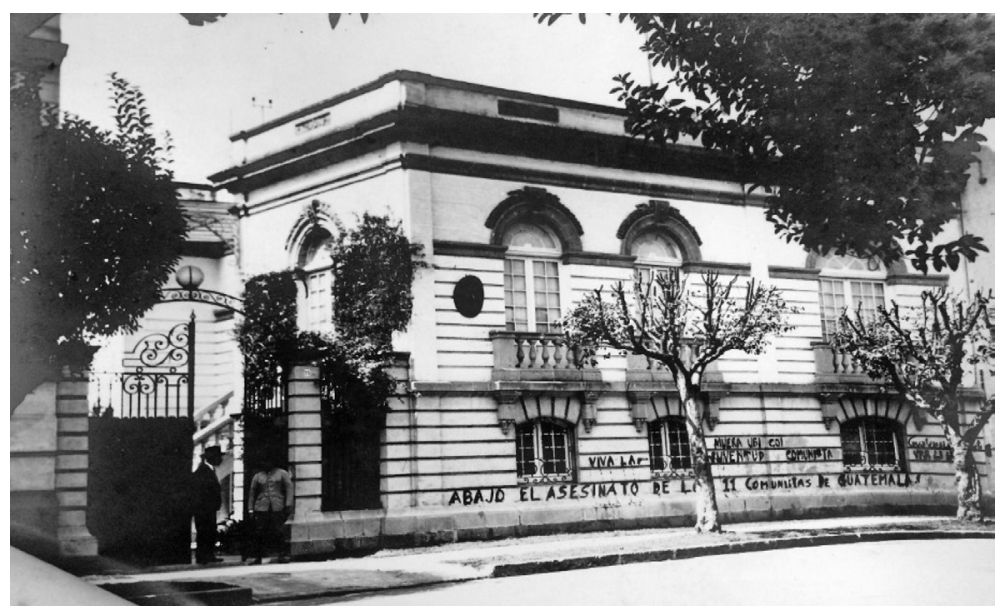

AGCA, RE, leg. 6725. 
botella, piedras y algunos panfletos. Días más tarde, el 16 de febrero por la noche, una manifestación tuvo lugar frente a la legación. El embajador denunció estas acciones ante las autoridades y envió a Guatemala una de las hojas volantes que lanzaron los protestantes. Tildaban a Ubico de fascista y asesino, aduciendo que apoyaban la lucha de la juventud obrera en Guatemala. La firma despejó las dudas sobre la autoría del atentado: el Comité Central de la Federación Juvenil Comunista de México. ${ }^{73}$

El secretario de Relaciones Exteriores, Manuel Téllez, prometió redoblar la vigilancia de la legación e investigar la procedencia de las amenazas que había recibido el embajador. En una de éstas intercalaron la exhortación a combatir el gobierno de Ubico con un mensaje hacia el diplomático: seguían sus pasos y planeaban un atentado. ${ }^{74} \mathrm{La}$ campaña fue intensa, pero no se limitó a la capital mexicana. Los comunistas radicados en Chiapas también participaron. Esta acción, aunada a la negligencia de los agentes migratorios mexicanos, condujo al régimen a tomar medidas en su frontera.

Bernabé Barrios, secretario general del Partido Comunista en Huehuetán, y Esteban Pérez, con el mismo cargo en Huixtla, enviaron una carta a Ubico en marzo de 1932. Alzaron su voz contra la ejecución de Wainwright y repudiaron "los procedimientos bárbaros de los chacales militaristas de ese gobierno, perro guardián de los intereses de Wall Street" ${ }^{75}$ Esta misiva fue elaborada cerca de la frontera, de donde arribaban, además, reportes inquietantes. En abril de 1932, el cónsul guatemalteco en

73 AGCA, B, RREE, exp. 6725 (12 de febrero de 1932).

74 AGCA, B, RREE, exp. 6725, el embajador guatemalteco en México al ministro de Relaciones Exteriores de Guatemala, México (sin fecha).

75 AGCA, B, RREE, exp. 6725, el secretario general de la filial del Partido Comunista de México en Huehuetán y Huixtla, Chiapas, al presidente constitucional de la República de Guatemala; Chiapas, México (1o de marzo de 1932). Un estudio sobre la organización y la actividad de los comunistas en el Soconusco durante este periodo aparece en GARCíA DE LEÓn, Resistencia y utopia, pp. 187-199. 
Mariscal, Chiapas, informó que había observado a un agente encubierto del gobierno mexicano intentando introducir a Guatemala a un prelado español sindicado de comunista y sedicioso. La misión se abortó por la intervención del jefe de migración de Ayutla, pero desde entonces vigilaron a las autoridades vecinas. ${ }^{76}$

Faltando seis meses para que la conferencia sobre migración se realizara, redoblaron la seguridad de la frontera con México y El Salvador. Cambiaron ciertas jefaturas y ordenaron seguir la pista de los individuos que merodeaban la frontera. La mención del señor presidente fue el sello que justificó las medidas y exigió su inmediatez. ${ }^{77} \mathrm{Y}$, precisamente, fue el mismo Ubico quien recibió en una audiencia especial a los delegados mexicanos una vez concluido su trabajo. Según Serrano, el gobernante se mostró complacido por la conferencia y anuente a evitar molestias para los ciudadanos de ambas naciones. "También indicó la idea que tiene de procurar que en lo sucesivo no emigren los braceros guatemaltecos hacia nuestro país, lo cual es conveniente para nosotros." 78 En esta plática, como se infiere de los archivos, Ubico calló su preocupación principal. No cabe duda que ocultar la intención real y expresar lo que el interlocutor quiere escuchar es la estrategia adecuada cuando se han adoptado las medidas pertinentes.

\section{CONCLUSIONES}

La conferencia de 1932 fue el primer encuentro formal entre los funcionarios guatemaltecos y mexicanos para abordar el

76 AGCA, B, RREE, exp. 6725, el cónsul de Guatemala en Mariscal, Chiapas, México, al ministro de Relaciones Exteriores de Guatemala (6 de abril de 1932).

77 AGCA, B, RREE, exp. 6725, el director general de la Policía Nacional al ministro de Relaciones Exteriores de Guatemala (24 de febrero de 1932).

78 AHSREM, III-1728-1, informe sobre juntas de migración (31 de agosto de 1932). 
tema migratorio. El intento más ceremonioso para eliminar esa "situación ambigua, por demás molesta y desagradable, no sólo para la región, sino para los gobiernos de Guatemala y México", como escribió Serrano. ${ }^{79}$ Ahora bien, ¿qué acuerdos se forjaron? Y, lo más importante, ¿por qué no tuvieron un impacto significativo en la dinámica fronteriza? La primera respuesta atañe a los problemas acuciantes que los delegados querían resolver y muestra, como telón de fondo, las buenas relaciones diplomáticas. Acordaron, por ejemplo, extender una tarjeta especial de identificación para que los residentes fronterizos visitaran y comerciaran en ambas naciones. Por otra parte, los mexicanos se comprometieron a realizar un censo de población y sus pares al registro de los extranjeros sin cobrarles por ello. Finalmente, delegaron a los cónsules de la zona fronteriza para que supervisaran este proceso, previniendo los malos tratos y deportaciones arbitrarias. Sin embargo, dejaron claro que todo aquel que ingresara a la nación vecina debía apegarse a las reglas migratorias y se comprometieron a evitar la salida de sus trabajadores. ${ }^{80}$

Después de la partida de los delegados mexicanos, el gobierno guatemalteco exhibió su beneplácito por el resultado de la conferencia en los periódicos. El comercio fronterizo se había reactivado y los personeros vecinos dejaron la capital centroamericana "impresionados por las atenciones de que fueron objeto y satisfechos por las resoluciones tomadas". ${ }^{81}$ Miguel Calderón, asesor jurídico de la delegación mexicana, coincidió con esta apreciación: expresó que los acuerdos consolidaban las relaciones cordiales entre los gobiernos y desdibujaban las

79 AHSREM, exp. III-1728-1, informe del embajador mexicano sobre la Conferencia de 1932 (31 de agosto de 1932).

80 AHSREM, exp. III-1728-1, convención entre México y Guatemala sobre asuntos de migración y residencia de los nacionales de un país en territorio de otro (agosto de 1932).

81 "Partió la delegación mexicana de migración”, El Liberal Progresista (10 sep. 1932), p. 2. 
discrepancias por las normas y procedimientos migratorios. Por otra parte, reiteró que habían cumplido las instrucciones de la Secretaría de Relaciones Exteriores, rehusándose a obtener ventajas "en detrimento de nuestro vecino del sur, sino únicamente soluciones equitativas a las muchas dificultades". ${ }^{82}$ Como es palpable, la suspicacia guatemalteca y el conocimiento que los mexicanos tenían de ésta no truncaron el acercamiento. De hecho, durante los años treinta la tónica bilateral fue ésa: apretones de mano en público y la crítica confinada a los informes confidenciales. Los guatemaltecos enfrentaban la crisis económica, y el maximato, entretanto, se hallaba en la etapa que Jürgen Buchenau definió como de estabilización (1927-1934), es decir, renunciando a inmiscuirse en los problemas centroamericanos. ${ }^{83}$

Empero, el acercamiento y los acuerdos de las delegaciones no propiciaron cambios significativos en la zona fronteriza, sólo aliviaron por un breve lapso los síntomas del problema. Al respecto, la Conferencia sirvió para establecer un trabajo conjunto, el cual quedó rezagado posteriormente. A principios de 1935, los personeros mexicanos resumieron el atolladero: las medidas estaban vigentes, "pero en la práctica se presentan dificultades casi insuperables". ${ }^{84}$ Por ejemplo, establecer la nacionalidad de muchos indocumentados que se amparaban con las disposiciones especiales del tratado limítrofe de $1882 .{ }^{85}$ Asimismo, la internación ilegal de los braceros continuaba y las trabas al comercio reaparecieron pronto. Incluso hubo protestas por las

\footnotetext{
82 AHSREM, exp. III-1728-1 (5 de septiembre de 1932), f. 44.

83 Buchenau, In the shadow of the giant, p. 160.

${ }^{84}$ AHSREM, exp. III-1728-1, acuerdo de la Secretaría de Gobernación para estudiar el problema demográfico de la frontera con Guatemala (18 de marzo de 1935).

${ }^{85}$ El artículo $5^{\circ}$ concedía la nacionalidad del país vecino al individuo que quedara del otro lado una vez definida la línea divisoria. Se estableció un tiempo para que la reclamaran, pero muchos nunca lo hicieron. En los años treinta esto generó problemas porque las autoridades mexicanas objetaron el testimonio como prueba.
} 
deportaciones arbitrarias. Pues bien, ¿qué factores generaron esta situación? ¿Por qué la dinámica fronteriza siguió por el sendero habitual?

Las respuestas hunden su raíz en la compleja situación de la frontera sur de México y la postura del gobierno presidido por Ubico. Como apunté en párrafos anteriores, los actores en la región del Soconusco eran diversos. Los finqueros y los políticos chiapanecos sacaban provecho del desorden imperante: los primeros para cosechar el café con mano de obra más barata y sin lidiar con los sindicatos; y los segundos, mientras tanto, para fortalecer una red clientelar que les aseguraba el voto de los guatemaltecos. En tal sentido, puede afirmarse que, si bien para el gobierno mexicano la presencia ilegal de los vecinos provocaba dificultades, para otros representaba ganancias. A esto respondió, en gran medida, el hecho de que la zona fronteriza continuara marcada por los problemas que la delegación mexicana quiso erradicar y, como dato primordial, que el presidente Lázaro Cárdenas decidiera formar la Comisión Demográfica Intersectorial en 1935.

Ahora bien, si al panorama interno se le agrega la posición del gobierno guatemalteco, el cuadro de la continuidad queda completo. Durante la crisis económica -es clave anotarlo-no le interesaba retener a sus trabajadores; por el contrario, le convenía restarle presión social a la región del altiplano, donde se habían registrado protestas y conatos de levantamientos. ${ }^{86} \mathrm{De}$ los archivos se infiere, entonces, que los intereses del régimen por la frontera eran evitar el ingreso de los comunistas que actuaban a sus anchas en México. Sellar la frontera, desde luego, pero para que las "ideas disolventes" no se esparcieran por su terruño.

${ }^{86}$ La oposición abierta de la población indígena a las políticas estatales "resurgió abiertamente de nuevo en la década de 1920, durante un decenio de inestabilidad política. La prensa informaba a menudo de levantamientos, resistencia a la autoridad estatal y de los finqueros". McCreery, "Mano de obra asalariada", pp. 349-383. 
De hecho, luego de la conferencia emitieron un decreto en el cual establecieron los caminos de tránsito legal hacia México. Además, fomentaron la denuncia ciudadana del contrabando, concediendo al delator el $50 \%$ de la mercancía incautada. Finalmente, obligaron a los propietarios de terrenos fronterizos "a prohibir el paso de extraños por sus predios" ${ }^{87}$ Así, el gobierno fortaleció su red de espionaje - una de sus notas constitutivas-y combatió la porosidad de su frontera. ${ }^{88}$

En síntesis, los intereses de los protagonistas de esta trama y los problemas afrontados muestran que para explicar por qué la Conferencia de 1932 no cambió la dinámica fronteriza no basta con citar -aunque sí se requiere- lo que la suscitó y los puntos acordados. Hace falta aplicar una dosis de sospecha ante la avenencia de los funcionarios. Dudar de la elocuencia de los funcionarios guatemaltecos, a sabiendas de lo que opinaban de México. Éste fue el objetivo que perseguí, precisamente, en este ensayo.

\section{SIGLAS Y REFERENCIAS}

AGCA, RE Archivo General de Centro América, fondo Relaciones Exteriores, Ciudad de Guatemala, Guatemala.

AHSREM Archivo Histórico Secretaría de Relaciones Exteriores, Ciudad de México, México.

AHCH-CUID Archivo Histórico de Chiapas. Centro Universitario de IF-CRE Información y Documentación. Inventario de Fomento, Colección Raymundo Enríquez, Chiapas, México.

Asturias, Miguel Ángel, El Señor Presidente, México, Lectorum, 2015.

Benjamin, Thomas, Chiapas: tierra rica, pueblo pobre. Historia social y politica, México, Grijalbo, 1995.

Brading, David (comp.), Caudillos y campesinos en la Revolución mexicana, México, Fondo de Cultura Económica, 2014.

87 AHSREM, exp. III-17-28-1 (I).

88 GRIEB, "El gobierno de Jorge Ubico". 
Buchenau, Jürgen, In the shadow of the giant. The making of Mexico's Central America policy, 1876-1930, Tuscalusa, The University of Alabama Press, 1996.

Carreras, Mercedes, Los mexicanos que devolvió la crisis 1929-1932, México, Secretaría de Relaciones Exteriores, 1974.

Castillo, Manuel, Mónica Toussaint, Mario Vázquez, Espacios diversos, historia en común, México, Secretaría de Relaciones Exteriores, 2006.

Coetzee, J. M., Foe, México, Penguin Random House, 2014.

Drinot, Paulo y Alan Knight (comps.), La Gran Depresión en América Latina, México, Fondo de Cultura Económica, 2015.

Figueroa, Carlos, "Marxismo, sociedad y movimiento sindical en Guatemala", en Anuario de Estudios Centroamericanos, 16: 1 (1990, pp. 57-86.

Figueroa, Carlos, "El bolchevique mexicano en la Centroamérica de los veinte" (entrevista con Jorge Fernández Anaya), en Memoria, 4: 31 (1990), pp. 212-223.

Fowler, Heather, "Caudillos revolucionarios en la década de 1920: Francisco Mújica y Adalberto Tejeda”, en Brading (comp.), 2014, pp. 211-238.

García de León, Antonio, Resistencia y utopia, México, Ediciones Era, 1985, tomo 2.

Gould, Jeffrey, "Dictadores indigenistas y los orígenes problemáticos de la democracia en Centroamérica", en Drinot y Knight (comps.), 2015, pp. 238-268.

Gould, Jeffrey y Aldo LAURIA, 1932: Rebelión en la oscuridad. Revolución, represión y memoria en El Salvador, El Salvador, Museo de la Palabra y la Imagen, 2014.

Grieb, Kenneth, "El gobierno de Jorge Ubico", en Historia General de Guatemala, tomo V. Época contemporánea 1898-1944, Guatemala, Asociación Amigos del País, 1996, pp. 43-60.

Gutiérrez, Harim, En el país de la tristeza. Las misiones diplomáticas de Federico Gamboa en Guatemala, México, Secretaría de Relaciones Exteriores, 2005. 
Knight, Alan, "Carácter y repercusiones de la Gran Depresión en México", en Drinot y Knight (comps.), 2015, pp. 269-307.

Lewis, Stephen, La Revolución ambivalente. Forjando Estado y nación en Chiapas. 1910-1945, México, Centro de Investigaciones Multidisciplinarias sobre Chiapas y la Frontera Sur, Universidad Nacional Autónoma de México, 2015.

Martínez, Germán, Plantaciones, trabajo guatemalteco y política migratoria en la frontera sur de México, México, Gobierno del Estado de Chiapas, Instituto Chiapaneco de Cultura, 1994.

McCreery, David, "Mano de obra asalariada, trabajo libre y leyes contra la vagancia: la transición al capitalismo en Guatemala, 1920-1945”, en RosebeRRY, SAMPER y GudMuson (comps.), 2001, pp. 351-383.

Melgar Bao, Ricardo, "Cominternismo intelectual: Representaciones, redes y prácticas político-culturales en América Central, 1921-1933”, en Revista Complutense de Historia de América, 35 (2009), pp. 135-159.

Nolan-Ferrell, Catherine, La construcción de la ciudadanía. Los trabajadores transnacionales y la revolución en la frontera México-Guatemala, 18801950, México, Centro de Investigaciones Multidisciplinarias sobre Chiapas y la Frontera Sur, Universidad Nacional Autónoma de México, 2018.

Roseberry, William, Mario SAmper y L. Gudmuson (comps.), Café, sociedad y relaciones de poder en América Latina, Costa Rica, Universidad Nacional de Costa Rica, 2001.

Obando Sánchez, Antonio, Memorias: la historia del movimiento obrero en Guatemala en este siglo, Guatemala Editorial Universitaria, 1978.

Secretaría del Trabajo y Previsión Social, Origen y repercusiones de la primera Ley Federal del Trabajo, México, Litografía Torres y Rosas, 1981.

Spenser, Daniela, En combate: la vida de Lombardo Toledano, México, Debate, 2018.

Spenser, Daniela, El triángulo imposible: México, Rusia Soviética y Estados Unidos en los años veinte, México, Centro de Investigaciones y Estudios Superiores en Antropología Social, Miguel Ángel Porrúa, 1998. 
Spenser, Daniela, El Partido Socialista Chiapaneco. Rescate y reconstrucción de su historia, México, Centro de Investigaciones y Estudios Superiores en Antropología Social, 1988.

Taracena, Arturo, “El primer Partido Comunista de Guatemala (1922-1923). Diez años de una historia olvidada", en Anuario de Estudios Centroamericanos, 15: 1 (1989), pp. 49-63.

Yankelevich, Pablo y Paola Chenillo, "El Archivo Histórico del Instituto Nacional de Migración”, en Desacatos, 26 (2014), pp. 25-42.

Zorrilla, Luis, Relaciones de México con la República de Centroamérica y Guatemala, México, Porrúa, 1984. 